\title{
Influenza Vaccine Coverage Among Children Under the Age of 5 YeARS IN POLAND DURING 2004-2008
}

\author{
A. Nitsch-Osuch ${ }^{1}$, E. Kuchar ${ }^{2}$, K. Zycinska ${ }^{1}$, A. Topczewska-Cabanek ${ }^{1}$, E. Gyrczuk ${ }^{1}$, K. Wardyn ${ }^{1}$ \\ ${ }^{1}$ Department of Family Medicine, Warsaw Medical University, Warsaw, Poland; ${ }^{2}$ Department of Pediatrics and Infectious Diseases, \\ Wroclaw Medical University, Wroclaw, Poland
}

\begin{abstract}
Introduction: Influenza is a considerable health problem all over the world. The most important group for influenza vaccination are children: the highest attack rate during community out-breaks of influenza can be found among school-aged children or their family members; children bear a considerable risk for complications due to influenza, leading to an increased need for healthcare resources (including hospitalization). The high level of vaccine coverage among school children could provide protection against influenza among households and could reduce mortality rates among older individuals.

Objective: The aim of this study was to estimate the influenza vaccine coverage among children younger than 5 years and to find any trends in influenza vaccine coverage in 2004-2008 in Poland.

Material and methods: Official data (number of administrated vaccines and the age of vaccinated individuals) collected by the National Institute of Hygiene, the National Institute of Public Health, and the Central Statistical Office in Poland were analyzed. This data are reported by physicians and collected from reports prepared annually by the Sanitary-Epidemiological Stations at a local level. The vaccine coverage rate was calculated as a percentage of vaccinated individuals among all children under the age of 5 years.

Results: The influenza vaccine coverage among children younger than 5 years varied from 1\% (2007 and $2008)$ to $1.9 \%$ (2005). The proportion of vaccinated children aged less than 5 compared with the total number of flu shots administrated irrespective of age also varied from $1.4 \%$ (2007) to $2 \%$ (2005).

Conclusions: The influenza vaccination coverage among Polish children aged less than 5 years is low and has persisted at the same level. More educational activities directed both to patients (parents) and healthcare workers would be needed to improve a general knowledge about influenza vaccination benefits among young children.
\end{abstract}

Key words: influenza, vaccine, coverage, children, Poland

\section{INTRODUCTION}

Influenza is a considerable health problem all over the world. According to the WHO estimation there are 3-
5 million cases of severe influenza, resulting in between 250000 and 500000 deaths worldwide each year [1]. The control of the diseases is based on the surveillance system, treatment, and prevention. Vaccines are a safe and effective method of preventing severe outcomes of influenza [2]. The focus of the vaccination strategies is more on the 'at risk' population rather than the whole population. There are large discrepancies in the definition of the word 'risk' and, consequently, vaccination coverage rates differ considerably. Aside from the traditional groups (the elderly and chronically ill patients), some other groups are regarded at higher risk of severe disease: pregnant women, children between the age of 2 and 5 years, individuals living with those at high risk, health care workers and other care workers, together with people working in military services [3].

There is no doubt that the most important group as far as influenza vaccination is concerned is that of children. It is known that the highest attack rate during community out-breaks of influenza can be found among school-aged children or family members [4]. Children bear a considerable risk for complications due to influenza, leading to an increased need for health care resources (including hospitalization) [5]. It was also shown that a high level of vaccine coverage among schoolchildren could provide protection against influenza among household contact and could even reduce mortality rates among older individuals [6].

The main new recommendation from the ACIP involves influenza vaccination for children from 6 months to 18 years of age. However, a routine vaccination of children between the ages of 6 and 59 months should continue to be a primary focus of influenza prevention because these children are at higher risk for complications of influenza [7].

In Europe recommendations for healthy children vaccinations are different, but generally vaccination against influenza is recommended to children younger than 2-5 years and all children older than 6 months with underlying symptoms. Currently only seven European countries propose to immunize healthy children and only three offer the vaccine at no cost for all children (Romania, Slovakia and Spain) [2]. In Poland influenza vaccines have been recommended since 1994, from 2010 the vaccine is recommended for all ill as well as healthy children aged 6 months to 18 years [8]. 
There is very little data concerning influenza vaccine coverage among children in Europe, so according to ECDC more studies on vaccination coverage rates of children are urgently required [2]. The aim of the present study was to estimate the influenza vaccine coverage among children younger than 5 years and to find any trends in influenza vaccine coverage in 20042008 in Poland.

\section{Material And Methods}

The review of coverage of influenza vaccination in Poland presented in this article was approved by a local Ethics Committee. Official data collected by the National Institute of Hygiene, the National Institute of Public Health (available on www.pzh.gov.pl), and the Central Statistical Office (available on www.stat.gov.pl) were analyzed. These data, concerning the number of doses of vaccines given to patients and age of vaccinated persons, are collected from the reports prepared by the Sanitary-Epidemiological Stations at local levels.

Data for these reports are supported from medical records by general practitioners who perform vaccinations in their practices. The vaccine coverage rate was calculated as a percentage of vaccinated individuals among all individuals at respective age ( $<5$ years).

\section{RESUlts}

The number of vaccines given to children younger than 5 years, the general number of children at this

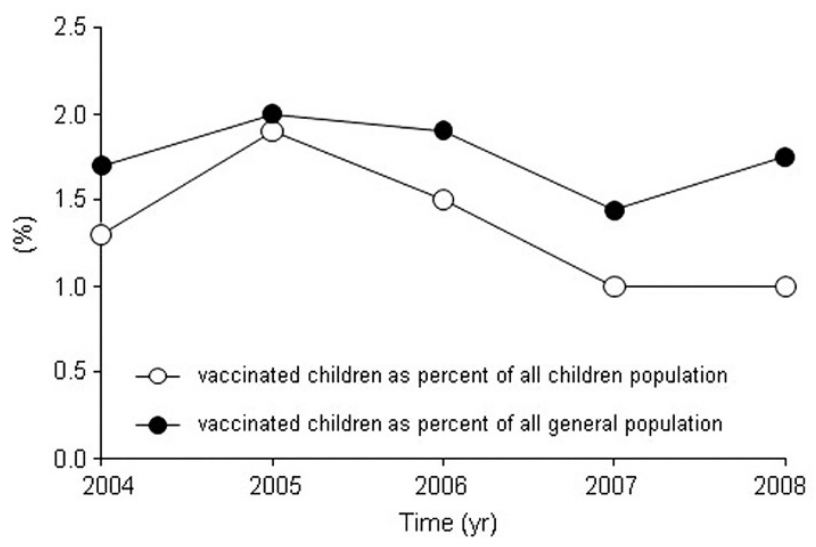

Fig.1. Influenza vaccine coverage among children aged $<5$ years in Poland during 2004-2008. age, and a total number of administrated vaccines for all individuals in Poland in 2004-2008 is illustrated in Table 1 . The influenza vaccine coverage among children younger than 5 years varied from 1\% (2007 and 2008) to $1.9 \%$ (2005) (Fig. 1).

\section{Discussion}

The influenza vaccine coverage among children younger than 5 years in Poland in 2004-2008 was extremely low, between $1-2 \%$. This is one more proof of a low uptake of influenza vaccinations within the Polish population - the influenza vaccine among general population is $5-8 \%$ [9].

Although there are very few data concerning influenza vaccine coverage among children in Europe, we may compare our date with the Spanish ones: the Spanish National Health Study identified the coverage at 7.0 and $6.5 \%$ among 6-23 months old and 2-15 years old healthy children, respectively [10]. In $2007 / 2008$ the influenza vaccine coverage ranged between $4.2 \%$ in Ireland and $19.3 \%$ in Germany $[2,11]$; these rates are also higher than the Polish ones. In Israel $2.7-6.5 \%$ of children were vaccinated against influenza in the 2003-2004 seasons [12]. Traditionally, the highest influenza coverage rates are observed in USA. An analysis of influenza vaccination coverage demonstrates that during 2004-2005, the first years of the recommendation for vaccination of children aged 6-23 months, 1 -dose coverage was 57\% [13], average coverage with $\geq 1$ doses among children aged 6-23 months increased from 40.8\% during the 2007-2008 influenza season to $47.8 \%$ during the 2008-2009 season 14].

Our data may be slightly underestimated because not all vaccinations against influenza might have been reported. Reporting of vaccinations is obligatory, although some physicians do not fulfill this duty; however, these are rare cases and should not strongly influence the overall result. Another problem which may influence our results is the lack of data on whether vaccination fulfilled the criteria; children younger than 8 years require two doses of vaccination when they are immunized for the first time in their life. The official data made available for our search did not provide enough information on how many vaccinated children were given the required two doses of the vaccine. Of note, the highest number of administrated influenza vaccines to both children and general population was observed in 2005, when first cases of avian influenza

Table 1. Demographic data and data concerning vaccination (number of doses) obtained from official sources and used for calculations.

\begin{tabular}{|c|c|c|c|c|c|}
\hline Year & 2004 & 2005 & 2006 & 2007 & 2008 \\
\hline $\begin{array}{l}\text { Number of children } \\
\text { aged }<5 \text { years }\end{array}$ & 1794481 & 1780631 & 1794481 & 1823446 & 1888342 \\
\hline $\begin{array}{l}\text { Number of influenza vaccines } \\
\text { given to children aged }<5 \text { years }\end{array}$ & 22637 & 33242 & 26804 & 19834 & 20346 \\
\hline $\begin{array}{l}\text { Number of influenza vaccines } \\
\text { given in the general population }\end{array}$ & 1356708 & 1603125 & 1371605 & 1212651 & 1158878 \\
\hline
\end{tabular}


among swans in Poland were noted. That might have been a possible reason of increased interest in influenza vaccination among parents of young children.

The purpose for the future should be to increase the influenza vaccine coverage among children in Poland; for both epidemiological (children are the reservoir of the disease and represent a primary pathway to transmit the infection to the household and to the community) and clinical reasons (children are at higher risk of severe course, complications and hospitalization of the disease). To realize higher coverage rates among children, the gain of data that quantify the burden of disease and the cost-effectiveness of vaccinating children could be the first step toward raising awareness of influenza vaccination among the government, healthcare providers, physicians, and parents [2]. The recommendation from a family doctor or nurse is the single most important encouraging factor for all vaccinations, including influenza.

In conclusion, influenza vaccination coverage among Polish children aged 0-5 years is too low (1$2 \%$ ) and has persisted at the same level during 20042008. More education showing the benefits of immunization should be provided to both parents of patients and health care providers to increase the general level of perception of how important, influenza vaccination among young children, really is.

Conflicts of interest: No conflicts of interests were declared by the authors in relation to this article.

\section{REFERENCES}

1. www. WHO. Influenza, fact sheet No 211(2008). www.who.int/mediacentre/factsheets/fs211/en.

2. Blank PR, Szucs TD. Increasing influenza vaccination coverage in recommended population groups in Europe. Expert Rev Vaccines 2009; 8(4): 425-33.

3. Mereckiene J, Cotter S, Weber JT. Low coverage of seasonal influenza vaccination in the elderly in many European countries. Euro Survell 2008; 13(41): 2-5.

4. American Academy of Pediatrics Committee on Infectious Diseases. Prevention of influenza: recommendations for influenza immunization of children, 2007-2008. Pediatrics 2008; 121(4): E1016-31.
5. Principi N, Esposito S. Are we ready for universal influenza vaccination in pediatrics? Lancet Infect Dis 2004; 4(2): 75-83.

6. Reichert TA, Sugaya N, Fedson D.S. The Japanese experience with vaccinating schoolchildren against influenza. N Engl J Med 2001; 344(12): 889-96.

7. CDC. Prevention and control of influenza. Recommendations of Advisory Committee on Immunization Practices. MMWR 2009; 56: 1-54.

8. National Programme on Immunizations in Poland. http://www.gis.gov.pl/userfiles/file/DepartamentPrzeci wepidemiczny/szczepienia/komunikatwspawiePS O2010.pdf

9. Brydak L. Influenza pandemic - a myth or a real threat? Znak, Warsaw 2008: 34-7.

10. Jimenez-Garcia R, Hernandez-Berrera V, Carrasco-Garrido P. Influenza vaccination coverages among children, adults, health care workers and immigrants in Spain: Related factors and trends. 2003-2006. J Infect 2008; 57(6): 472-80.

11. Blank PR, Schwenkglenks M, Szuks TD. Vaccination coverage rates in eleven European countries during two consecutive influenza seasons. J Infect 2008; 58(6): 446-58.

12. Stein M. Influenza vaccine coverage in paediatric population from central Israel. J Infect 2005; 50(5): 382-5.

13. CDC. Influenza vaccination coverage among children aged 6-59 months - six immunization information system sentinel sites. United States, 2006-7 influenza season. MMWR 2007; 56(37): 963-5.

14. Influenza vaccination coverage among children aged 6 months-18 years - eight immunization information system sentinel sites. United States, 2008-09 influenza season. MMWR Morb Mortal Wkly Rep 2009; 58(38): 1059-62.

Address for correspondence:

Aneta Nitsch-Osuch

Department of Family Medicine

Medical University of Warsaw

1A Banacha St.

02-097 Warsaw

Poland

Phone: +48 225992190

Fax: +48 225992178

E-mail: anitsch@amwaw.edu.pl 